\title{
Acute coronary syndromes in the community
}

Sheila M. Manemann, MPH ${ }^{1}$, Yariv Gerber, $\mathrm{PhD}^{1,3}$, Alanna M. Chamberlain, $\mathrm{PhD}, \mathrm{MPH}^{1}$, Shannon M. Dunlay, MD, MSc${ }^{2}$, Malcolm R. Bell, MD², Allan S. Jaffe, MD², Susan A. Weston, $\mathbf{M S}^{1}$, Jill M. Killian, BS ${ }^{1}$, Jan Kors, $\mathrm{PhD}^{4}$, and Véronique L. Roger, MD, MPH ${ }^{1,2}$

${ }^{1}$ Department of Health Sciences Research, Mayo Clinic, Rochester, Minnesota, USA ${ }^{2}$ Division of Cardiovascular Diseases in the Department of Internal Medicine, Mayo Clinic, Rochester, Minnesota, USA ${ }^{3}$ Department of Epidemiology and Preventive Medicine, School of Public Health, Sackler Faculty of Medicine, Tel Aviv University, Tel Aviv, Israel ${ }^{4}$ Department of Informatics, Erasmus University Medical Center, Rotterdam, Netherlands

\section{Abstract}

\begin{abstract}
Aims-To measure the incidence of acute coronary syndrome (ACS), defined as first ever myocardial infarction (MI) or unstable angina (UA); evaluate recent temporal trends; and determine if survival after ACS has changed over time and differs by type.

Patients and Methods-This was a population surveillance study conducted in Olmsted County, Minnesota (population: 144,248). All persons hospitalized with incident ACS between $1 / 1 / 2005-12 / 31 / 2010$ were identified using ICD-9 codes, natural language processing of the medical records and biomarkers. MI was validated by epidemiological criteria and UA by the Braunwald classification. Patients were followed through 6/30/2013 for death.
\end{abstract}

Results-Among 1,244 incident ACS cases, 35\% were UA and 65\% were MI. The standardized rates (per 100,000) of ACS were 284 (95\% CI: 248-319) in 2005 and 184 (95\% CI: 157-210) in 2010 (2010 vs. 2005 RR 0.62; 95\% CI: 0.53-0.73), indicating a 38\% decline (similar for MI and UA). The 30-day case fatality rates did not differ by year of diagnosis, but were worse for MI (8.9\%; 95\% CI: 6.9\%-10.9\%) compared to UA (1.9\%; 95\% CI: 0.6\%-3.1\%). Among 30-day survivors, the risk of death did not differ by ACS type or diagnosis year.

Conclusions-In the community, UA constitutes 35\% of ACS. The incidence of ACS declined in recent years and trends were similar for UA and MI reaffirming a substantial decline in all acute manifestations of coronary disease. Survival after ACS did not change over time, but 30-day survival was worse for MI compared to UA.

(C) 2015 Published by Mayo Foundation for Medical Education and Research.

Address for Correspondence: Véronique L. Roger, MD, MPH; Mayo Clinic; 200 First Street SW; Rochester, MN 55905; phone (507) 538-6916; FAX (507) 284-1516; roger.veronique@ mayo.edu.

Publisher's Disclaimer: This is a PDF file of an unedited manuscript that has been accepted for publication. As a service to our customers we are providing this early version of the manuscript. The manuscript will undergo copyediting, typesetting, and review of the resulting proof before it is published in its final citable form. Please note that during the production process errors may be discovered which could affect the content, and all legal disclaimers that apply to the journal pertain.

Conflict of interest

Dr. Jaffe acknowledges that he does or previously has consulted with most of the major diagnostic companies. All other authors report no conflicts of interest. 


\section{Keywords}

Acute Coronary Syndrome; Myocardial Infarction; Unstable Angina; Epidemiology; Survival

\section{Introduction}

Cardiovascular disease is the leading cause of death in the United States. ${ }^{1}$ Specifically, coronary heart disease (CHD) caused approximately 1 out of every 6 deaths in the US in 2009. ${ }^{1}$ The need for surveillance of coronary disease is recognized and, absent a national surveillance system, relies largely on community studies. ${ }^{2}$

Over the past decade, a major change in the epidemiology of myocardial infarction (MI) has been documented with a profound decline in MI incidence and, in particular, ST elevation MI. ${ }^{3-6}$ Short term mortality after MI has also declined. ${ }^{3-6}$ However, the epidemiology of acute coronary syndrome (ACS), including both MI and unstable angina (UA), is not well studied and to our knowledge, only one recent study in Australia has evaluated the incidence of ACS, including both MI and UA. ${ }^{7}$ This study reported a decline in the incidence of hospitalized ACS from 1996-2007; however it relied solely on codes to classify events and did not report outcomes.

Thus, to address these gaps in knowledge, we measured the incidence of ACS, defined as first ever MI or UA, in a geographically defined population and evaluated recent temporal trends. Furthermore, we described survival after incident ACS, to determine whether it changed over time or differed by ACS type (MI or UA).

\section{Methods}

\section{Study setting}

This study was conducted in Olmsted County, Minnesota which has a population of 144,248 according to the 2010 US census. We utilized the resources of the Rochester Epidemiology Project (REP), a medical records linkage system that links and archives the medical records of virtually all persons residing in the county..$^{8,9}$ The REP maintains an electronic index of medical diagnoses and can identify patients through their outpatient and hospital contacts across all local medical providers. ${ }^{10}$ The resources of the REP have been used in cardiovascular disease epidemiology research published extensively over the years. ${ }^{11-13}$

\section{Ascertainment of hospitalized incident ACS}

Myocardial infarction-All patients admitted to Mayo Clinic Hospital - Rochester between January 1, 2005 and December 31, 2010 who had a troponin T level of $0.03 \mathrm{ng} / \mathrm{mL}$ or higher and were assigned diagnoses compatible with MI were identified. The target codes from the International Classification of Diseases, Ninth Revision (ICD-9 CM) included 410 (acute MI), 411 (other acute and subacute forms of ischemic heart disease), 412 (old myocardial infarction), 413 (angina pectoris) and 414 (other forms of ischemic heart disease). 
As we previously reported, ${ }^{3,14}$ validation of MI relied on standard algorithms integrating cardiac pain, electrocardiographic (ECG) and biomarker data. According to current guidelines, each case was classified by troponin T. ${ }^{15}$ Systematic troponin $\mathrm{T}$ testing was initiated in 2000 and was fully implemented over the study period. The presence or absence of a change (rise or fall) between any two troponin $\mathrm{T}$ measurements was defined by a difference of at least $0.05 \mathrm{ng} / \mathrm{mL}$, which is greater than the level of imprecision of the assay at all concentrations. ${ }^{15}$ Circumstances which might invalidate biomarker values were recorded. ${ }^{16}$ Troponin $\mathrm{T}$ was measured with a sandwich electrochemiluminescence immunoassay on the Elecsys 2010 (Roche Diagnostics Corporation; Indianapolis, Indiana) in the laboratories of the Department of Laboratory Medicine and Pathology which is certified by the Clinical Laboratory Improvement Act of 1988 and the College of American Pathologists, with robust quality control in place.

Up to three electrocardiograms per episode were coded using the Minnesota Code Modular ECG Analysis System. ${ }^{17}$ According to the algorithm, MIs were classified as definite, probable, suspect or no infarction. ${ }^{14,} 18$ We defined MI as an incident (first-ever) MI classified as definite or probable or a suspect MI with death occurring within 48 hours.

Unstable angina-UA cases were identified among patients admitted to Mayo Clinic Hospital - Rochester between January 1, 2005 and December 31, 2010, who underwent a troponin T measurement and were assigned an ICD-9 code 410-414. Natural language processing of the unstructured text of the electronic medical record was used to identify patients with clinical findings comparable with UA, including descriptive terms of type and location of pain (i.e., chest pain, substernal pain). The potential UA cases that were identified by this process were manually reviewed by nurse abstractors. The validation of UA relied on the Braunwald definition for first-ever primary UA (developed in the absence of an extracardiac condition) or secondary UA (developed in the presence of an extracardiac condition that intensified myocardial ischemia). ${ }^{19}$

If an individual experienced both an MI and UA during the study period, the first event was considered the incident ACS event. To determine which event was the first, the totality of the community medical record for all patients was reviewed. Notes were reviewed for any indication of MI or UA and all events were validated according to the above described standardized criteria. Patients with an MI or UA before 2005 were excluded from the study.

Ascertainment of clinical characteristics-Demographic and clinical characteristics at the time of incident ACS were collected from the medical records by nurse abstractors. Clinicians' diagnoses were used to define hypertension, hyperlipidemia, diabetes, heart failure, chronic obstructive pulmonary disease, familial coronary disease, and smoking status. Comorbidity was measured by the Charlson comorbidity index..$^{20}$ Estimated glomerular filtration rate (eGFR) was calculated using the creatinine value closest to ACS diagnosis ( \pm 1 year) with the Modification of Diet in Renal Disease Study equation. ${ }^{21}$

Body mass index (BMI) $\left(\mathrm{kg} / \mathrm{m}^{2}\right)$ was calculated using height and weight at the time of the ACS event. 
The severity of the MI was evaluated using several indicators. ${ }^{3}$ The Killip class served as the indicator of hemodynamic severity on admission. ${ }^{22}$ Cardiogenic shock (Killip class IV) was defined as a systolic blood pressure under $90 \mathrm{mmHg}$ in the absence of hypovolemia. The presence of ST-segment elevation and Q waves was ascertained using the Minnesota code of the ECG. ${ }^{17}$ Reperfusion or revascularization (percutaneous coronary intervention, coronary artery bypass graft and thrombolysis) during the ACS hospitalization was collected from the medical records.

Outcome ascertainment-Participants were followed for death from any cause through June 2013. Deaths were obtained from inpatient and outpatient medical records, as well as death certificates which are received on a quarterly basis from Olmsted County and the state of Minnesota. Cardiovascular cause of death was based on codes from the 10th version of the International Classification of Diseases, while relying on the American Heart Association categories for cardiovascular deaths (I00 to I99). ${ }^{1}$

\section{Statistical analysis}

Baseline characteristics are presented as frequencies (percent) for categorical variables, mean (SD) for normally-distributed continuous variables and median $\left(25^{\text {th }}, 75^{\text {th }}\right.$ percentile $)$ for continuous variables with a skewed distribution. Chi-square tests and Wilcoxon rank sum tests were used to test differences between ACS types and year group.

Age-, gender-, type of ACS-, and year-specific incidence rates of ACS were calculated. The denominators were determined by Olmsted County population data. These rates were directly standardized to the age and sex distribution of the US 2010 population and the rate ratio (RR) of ACS in 2010 compared to 2005 was estimated using Poisson regression. A linear and a quadratic component for year and age were tested. All 2-way interactions were tested.

Mortality within 30-days and mortality among 30-day survivors was analyzed with the Kaplan-Meier method according to year category (2005-2007 and 2008-2010) and ACS type and compared with the log-rank test. Cox proportional hazards regression was used to determine whether survival differed by year of diagnosis or ACS type while adjusting for age, sex, Charlson comorbidity index and reperfusion/revascularization. The proportional hazards assumption was tested using the scaled Schoenfeld residuals and found to be not valid. Consequently, the follow-up period was dichotomized at 30 days which resulted in the proportional hazards assumption being met. A $P$-value less than .05 was used as the level of statistical significance, except when testing interactions when a $P$-value of less than .10 was used.

Analyses were performed using SAS version 9.2 (SAS Institute Inc, Cary, NC). All aspects of the study were approved by the appropriate Institutional Review Boards. 


\section{Results \\ Clinical characteristics}

Between 2005 and 2010, 2898 potential incident ACS cases were identified in Olmsted County, Minnesota. Of these, 1,244 incident ACS events (806 [65\%] MI, 438 [35\%] UA) were validated. Of the 1,244 incident ACS cases, clinical and follow-up data were available for 1,221 (98\%). The mean (SD) age at the incident ACS event was 67.7 (14.7) years and $59 \%$ were men; neither the age nor the sex distribution differed between MI and UA ( $P=.54$ and .14, respectively) or between year groups of 2005-2007 and 2008-2010 ( $P=.42$ and .12, respectively). Patients whose incident ACS event was UA were more likely to have a history of hypertension, hyperlipidemia and heart failure (Table 1). Furthermore, patients with UA had a higher BMI and lower Killip class and were less likely to receive reperfusion or revascularization. The clinical characteristics of the ACS patients were similar between year groups (2005-2007 and 2008-2010) with the exception of a higher proportion of patients having a history of hyperlipidemia and diabetes, a higher BMI and higher eGFR and lower Killip class in the more recent time period (Table 1). Notably, of those whose incident ACS event was an MI, the proportion of ST elevation MI was $23 \%$ and did not change over the study period $(P=.60)$.

\section{Incidence of ACS}

The overall age- and sex-standardized incidence rate of ACS per 100,000 persons was 219 (95\% CI: 207-232) during the period 2005 to 2010 . The MI standardized rate per 100,000 was 142 (95\% CI: 132-152) and for UA it was 77 (95\% CI: 70-84). The incidence rate of ACS per 100,000 declined from 284 (95\% CI: 248-319) in 2005 to 184 (95\% CI: 157-210) in 2010 (RR: 0.62 ; 95\% CI: 0.53-0.73), equating to a 38\% decline. The magnitude of the decline was similar for MI and UA ( $P$ for ACS type*year interaction=.25; Figure 1$)$. The decline in the incidence of ACS from 2005 to 2010 appeared to be greatest among the oldest age group in both men and women ( $P$ for year*age interaction=.03; Table 2$)$.

\section{Mortality}

Within the first 30 days post-ACS diagnosis, 78 patients died. The overall 30-day case fatality rate was $6.4 \%$ (5.0-7.8\%) and did not differ by year of diagnosis (unadjusted HR for 2010 vs. 2005: 1.13; 95\% CI: 0.59-2.15; Table 3). Results were similar after adjustment for sex, age, ACS type, Charlson comorbidity index and reperfusion/revascularization (adjusted HR for 2010 vs. $2005: 1.47$; $95 \%$ CI: $0.76-2.85$; Table 3 ). The 30-day case fatality rate was higher for MI (8.9\%; 95\% CI: 6.9-10.9\%) than UA (1.9\%; 95\% CI: $0.6-3.1 \%), P<.001$ (Figure 2). The unadjusted 30-day mortality HR (95\% CI) for MI vs. UA was 5.00 (95\% CI: 2.41-10.39; Table 3). Results were similar after adjustment for sex, age, year of ACS, Charlson comorbidity index and reperfusion/revascularization.

Among the 30-day survivors, 265 deaths occurred during a mean (SD) follow-up of 4.5 (2.1) years, of which 103 (39\%) were from cardiovascular causes. There was no significant difference in survival between those with ACS in 2010 vs. 2005 (unadjusted HR: 0.84; 95\% CI: 0.56-1.27; Table 3). Adjustment for sex, age, ACS type, Charlson comorbidity index and reperfusion/revascularization did not change these results (adjusted HR for 2010 vs. 2005: 
0.88; 95\% CI: 0.58-1.34; Table 3). One-year mortality rates were similar for MI (6.0\%; $95 \%$ CI: 4.3-7.8) and UA (6.6\%; 95\% CI: 4.2-9.0\%), log-rank $P=.82$ (Figure 2). There was no detectable difference in survival between MI and UA (unadjusted HR: $1.03 ; 95 \% \mathrm{CI}$ : 0.80-1.32; Table 3). Adjustment for sex, age, year of ACS, Charlson comorbidity index and reperfusion/revascularization did not substantially affect these results.

\section{Discussion}

These population-based data from Olmsted County, Minnesota, indicate that approximately one-third of ACS present as UA in the community and that the incidence of ACS declined substantially between 2005 and 2010. The rate of decline was similar for both MI and UA. Overall, survival after ACS did not change during the study period. While 30-day survival was worse for MI than UA, long-term survival was similar for both MI and UA.

\section{ACS in the community}

The ascertainment of UA in community studies is challenging. Indeed, relying on diagnostic codes may be of uncertain reliability but manual validation is time consuming. In this context, there are few published data on surveillance of coronary disease that includes UA. This is important as it is not known if the recently reported decline in $\mathrm{MI}^{3,4}$ could be offset by opposite trends in UA.

Using diagnostic codes, data from the Western Australian Data Linkage System reported that UA constituted 35\% of ACS. ${ }^{7}$ Data from the National Hospital Discharge Survey and the National Heart, Lung and Blood Institute indicated that approximately $30 \%$ of 1.1 million discharges for ACS in 2010 were due to UA. ${ }^{1}$ Similarly, the expanded Global Registry of Acute Coronary Events (GRACE) study, which is a prospective, multinational study of patients hospitalized with ACS, found that among 31,982 patients enrolled from 2001 to $2007,26 \%$ had UA. ${ }^{23}$ In the community of Olmsted County, Minnesota, we report that UA accounts for $35 \%$ of all ACS in the community. The present study used rigorous case validation using standardized definitions and supports the validity of the aforementioned previous reports, which relied on administrative or registry data.

\section{Incidence of ACS}

The data on temporal trends in ACS are sparse. In the 1988-2001 Nationwide Inpatient Sample from the USA, rates of first-listed UA fell 87\% from 29.7/10000 in 1988 to $3.9 / 10000$ in 2001 , but as acknowledged by the authors, since the data relied on diagnostic codes, misclassification could not be ruled out. ${ }^{24}$ Over similar periods, declines in hospitalizations for UA were reported using different administrative data sources, including Medicare claims of SEER-Medicare control subjects and the National Hospital Discharge Survey. ${ }^{25,} 26$ Outside the USA, and within the Western Australian Data Linkage System, a significant decline in ACS was noted between 1996 and 2007. ${ }^{7}$ The rate of ACS declined annually by approximately $1.7 \%$ with a greater decline in UA compared to MI over time. Finally, in Canada, the hospitalizations for ACS fell 38\% from 1994 to 2005. ${ }^{27}$

Taken collectively, these studies raise the critical question of a major change in the epidemiology of ACS but cannot provide a definitive answer as they share substantive 
limitations including reliance on administrative data. Additionally, possible confounding due to temporal changes in biomarkers and/or assays could have masked a decline in MI incidence. Thus, the provocative question of a disappearance of hospitalized UA remained unanswered, requiring robust methods to provide the needed response. The present data addresses this critical gap in knowledge by showing that, in recent years (2005 to 2010), the incidence of all validated ACS in the community declined by $38 \%$. The rate of decline was similar for both MI and UA and was the greatest among those aged 80 and older. This decline is substantial and occurred over a short period of time. As all cases were validated, a coding artifact is unlikely to explain these findings. The same biomarker and assay were used throughout the study period ruling out confounding by this factor as an alternate explanation for the trend.

Interpreting these findings requires integrating them with previous reports of a major change of the epidemiology of MI that we and others have previously reported. In the Atherosclerosis Risk in Communities (ARIC) study, from 1987 to 2008 the age-, biomarker-, and race-adjusted average annual rate of incident MI decreased 3.8\% for men and $3.5 \%$ for women. ${ }^{5}$

A report from Kaiser Permanente group showed a $24 \%$ relative decrease in the incidence of MI from 1999 to $2008 .{ }^{4}$ The Worcester Heart Attack Study also reported declining incidence rates of MI (277 per 100,000 in 1975 to 209 per 100,000 in 2005). ${ }^{6}$ In Denmark, a large decline in the incidence of hospitalized MI was reported from 1984 to 2008 (37\% for women and $48 \%$ for men). ${ }^{28}$ Similarly, in England the MI event rate fell $33 \%$ for men and $31 \%$ for women from 2002 to $2010 .{ }^{29}$ Finally, we had reported a 33\% decline in the incidence of MI in Olmsted County from July 1, 2000 to March 31, 2009. ${ }^{30}$ The present data reaffirms the decline of $\mathrm{MI}$ and brings forth important new knowledge in demonstrating that this decline is not offset by an increase in hospitalized UA, which had been one of the hypotheses that followed the aforementioned reports on the decline in the incidence of MI. To the contrary, the decline in UA is of the same magnitude, indicating that it pertains to all acute manifestations of coronary disease. The robust documentation of a large recent decline in the incidence of all ACS constitutes a striking observation, for which several explanations can be offered. Concomitant favorable trends in risk factors in the general population likely play a role, ${ }^{31-34}$ thereby implying a possible decline in the occurrence of coronary disease. It is also conceivable that care of coronary disease is shifting to the outpatient setting as chronic angina may become more frequent than acute events such as ACS. Future studies will be needed to test this hypothesis.

\section{ACS mortality}

We did not detect a temporal change in survival after incident ACS within the first 30 days or among 30-day survivors. To the best of our knowledge, few studies have reported on survival trends post incident ACS. In prior years, between 1999 and 2006, a reduction in inhospital death for ST-elevation MI and non-ST elevation ACS was reported in GRACE, which also reported a reduction in death within 6-months for non-ST elevation ACS but not for ST elevation MI. ${ }^{35}$ Similar results were reported from the Australian and New Zealand cohort of GRACE from 2000-2007. ${ }^{36}$ Further, several studies of MI have reported on trends 
in short-term mortality. In the ARIC study, 28-day case fatality declined by $3 \%$ per year from 1987 to $2008 .{ }^{5}$ Data from Kaiser Permanente indicated a 24\% reduction in 30-day mortality from 1999 to $2008 .{ }^{4}$ The 30-day case fatality rates also declined in the Worcester Heart Attack Study from $17.6 \%$ in 1975 to $11.9 \%$ in $2005 .{ }^{6}$ Finally, in Olmsted County we found a 56\% decline in the risk of death within 30 days post incident MI from 1987 to 2006, contrasting with a lack of any detectable change in mortality among 30-day survivors. ${ }^{3}$ The present study brings about new current knowledge by reporting that thirty-day case fatality rates were worse for those whose incident ACS event was an MI than for those with UA. However, beyond 30 days, the mortality risk between MI and UA was similar.

\section{Limitations}

Some limitations should be acknowledged to aid in the interpretation of the data. We relied on the ICD-9 codes 410-414 to identify potential ACS cases and thus individuals without one of these codes would not have been included in the screening process. We had limited statistical power for detecting differences in post-ACS survival or examining cause-specific death. Furthermore, as with any study, the racial and ethnic composition of the population may limit the generalizability to ethnic groups not adequately represented in the population. This does not limit the impact of our findings, which provide important new information on the epidemiology of ACS, which are lacking to date. Moreover, the population of Olmsted County, Minnesota, is representative of the state of Minnesota and the Upper Midwest region of the US. ${ }^{37}$

\section{Clinical Implications and Conclusions}

The present study has important implications for understanding the contemporary epidemiology of ACS. We quantified the burden of ACS, including both MI and UA, in the community. Until now, it was unclear if trends in hospitalized UA could have been offsetting trends in MI, thereby merely representing a shift along the spectrum of acute coronary disease. We present strong evidence that this is not the case as the incidence of all ACS is declining and that the trends are similar for both MI and UA, thereby underscoring that all acute manifestations of coronary disease have declined in recent years. While MI had worse short-term survival than UA, there was no difference in long-term survival by ACS type.

This major change in the epidemiology of all ACS with its unanticipated decline in occurrence contributes to declining volumes of revascularizations. ${ }^{38,39}$ Importantly, the potential impact of declining incidence of disease could not by design have been addressed in these studies of health care utilization. Thus our data inform a matter of great importance for patient care, public health and policy, and training of the next generation of cardiologists.

\section{Acknowledgments}

We thank Susan Stotz, RN, Ellen Koepsell, RN and Deborah S. Strain for their study support. Dr. Roger had full access to all the data in the study and takes responsibility for the integrity of the data and the accuracy of the data analysis.

Funding 
This work was supported by the National Heart, Lung and Blood Institute of the National Institute of Health, Bethesda, Maryland [R01HL59205 to VLR] and study data were obtained from the Rochester Epidemiology Project, which is supported by the National Institute on Aging of the National Institutes of Health, Bethesda, Maryland, under Award Number [R01AG034676]. The content is solely the responsibility of the authors and does not necessarily represent the official views of the National Institutes of Health. The National Institutes of Health played no role in the design and conduct of the study; collection, management, analysis, and interpretation of the data; preparation, review or approval of the manuscript; and decision to submit the manuscript for publication.

\section{References}

1. Go AS, Mozaffarian D, Roger VL, Benjamin EJ, Berry JD, Borden WB, Bravata DM, Dai S, Ford ES, Fox CS, Franco S, Fullerton HJ, Gillespie C, Hailpern SM, Heit JA, Howard VJ, Huffman MD, Kissela BM, Kittner SJ, Lackland DT, Lichtman JH, Lisabeth LD, Magid D, Marcus GM, Marelli A, Matchar DB, McGuire DK, Mohler ER, Moy CS, Mussolino ME, Nichol G, Paynter NP, Schreiner PJ, Sorlie PD, Stein J, Turan TN, Virani SS, Wong ND, Woo D, Turner MB. Heart disease and stroke statistics--2013 update: a report from the American Heart Association. Circulation. 2013; 127(1):e6-e245. [PubMed: 23239837]

2. Goff DC Jr. Brass L, Braun LT, Croft JB, Flesch JD, Fowkes FG, Hong Y, Howard V, Huston S, Jencks SF, Luepker R, Manolio T, O'Donnell C, Robertson RM, Rosamond W, Rumsfeld J, Sidney $\mathrm{S}$, Zheng ZJ. Essential features of a surveillance system to support the prevention and management of heart disease and stroke: a scientific statement from the American Heart Association Councils on Epidemiology and Prevention, Stroke, and Cardiovascular Nursing and the Interdisciplinary Working Groups on Quality of Care and Outcomes Research and Atherosclerotic Peripheral Vascular Disease. Circulation. 2007; 115(1):127-55. [PubMed: 17179025]

3. Roger VL, Weston SA, Gerber Y, Killian JM, Dunlay SM, Jaffe AS, Bell MR, Kors J, Yawn BP, Jacobsen SJ. Trends in incidence, severity, and outcome of hospitalized myocardial infarction. Circulation. 2010; 121(7):863-9. [PubMed: 20142444]

4. Yeh RW, Sidney S, Chandra M, Sorel M, Selby JV, Go AS. Population trends in the incidence and outcomes of acute myocardial infarction. N Engl J Med. 2010; 362(23):2155-65. [PubMed: 20558366]

5. Rosamond WD, Chambless LE, Heiss G, Mosley TH, Coresh J, Whitsel E, Wagenknecht L, Ni H, Folsom AR. Twenty-two-year trends in incidence of myocardial infarction, coronary heart disease mortality, and case fatality in 4 US communities, 1987-2008. Circulation. 2012; 125(15):1848-57. [PubMed: 22420957]

6. Floyd KC, Yarzebski J, Spencer FA, Lessard D, Dalen JE, Alpert JS, Gore JM, Goldberg RJ. A 30year perspective (1975-2005) into the changing landscape of patients hospitalized with initial acute myocardial infarction: Worcester Heart Attack Study. Circ Cardiovasc Qual Outcomes. 2009; 2(2): 88-95. [PubMed: 20031820]

7. Nedkoff LJ, Briffa TG, Preen DB, Sanfilippo FM, Hung J, Ridout SC, Knuiman M, Hobbs M. Ageand sex-specific trends in the incidence of hospitalized acute coronary syndromes in Western Australia. Circ Cardiovasc Qual Outcomes. 2011; 4(5):557-64. [PubMed: 21862718]

8. Melton LJ 3rd. History of the Rochester Epidemiology Project. Mayo Clin Proc. 1996; 71(3):26674. [PubMed: 8594285]

9. Rocca WA, Yawn BP, St Sauver JL, Grossardt BR, Melton LJ. History of the Rochester Epidemiology Project: Half a Century of Medical Records Linkage in a US Population. Mayo Clin Proc. 2012; 87(12):1202-13. [PubMed: 23199802]

10. St Sauver JL, Grossardt BR, Yawn BP, Melton LJ 3rd, Rocca WA. Use of a medical records linkage system to enumerate a dynamic population over time: the Rochester Epidemiology Project. Am J Epidemiol. 2011; 173(9):1059-68. [PubMed: 21430193]

11. Roger VL, Weston SA, Redfield MM, Hellermann-Homan JP, Killian J, Yawn BP, Jacobsen SJ. Trends in heart failure incidence and survival in a community-based population. JAMA. 2004; 292(3):344-50. [PubMed: 15265849]

12. Bursi F, Weston SA, Redfield MM, Jacobsen SJ, Pakhomov S, Nkomo VT, Meverden RA, Roger VL. Systolic and diastolic heart failure in the community. JAMA. 2006; 296(18):2209-16. [PubMed: 17090767] 
13. Adabag AS, Therneau TM, Gersh BJ, Weston SA, Roger VL. Sudden death after myocardial infarction. JAMA. 2008; 300(17):2022-9. [PubMed: 18984889]

14. Roger VL, Jacobsen SJ, Weston S, Goraya TY, Killian J, Reeder GS, Kottke TE, Yawn BP, Frye RL. Trends in the Incidence and Survival of Patients with Hospitalized Myocardial Infarction, Olmsted County, Minnesota, 1979 to 1994. Ann Intern Med. 2002; 136:341-8. [PubMed: 11874305]

15. Alpert JS, Thygesen K, Antman E, Bassand JP. Myocardial infarction redefined--a consensus document of The Joint European Society of Cardiology/American College of Cardiology Committee for the redefinition of myocardial infarction. J Am Coll Cardiol. 2000; 36(3):959-69. [PubMed: 10987628]

16. Jaffe AS. Elevations of troponin - false false-positives: the real truth. Cardiovasc Toxicol. 2001; 1(2):87-92. [PubMed: 12213978]

17. Kors JA, Crow RS, Hannan PJ, Rautaharju PM, Folsom AR. Comparison of computer-assigned Minnesota Codes with the visual standard method for new coronary heart disease events. Am J Epidemiol. 2000; 151(8):790-7. [PubMed: 10965976]

18. White AD, Folsom AR, Chambless LE, Sharret AR, Yang K, Conwill D, Higgins M, Williams OD, Tyroler HA. Community surveillance of coronary heart disease in the Atherosclerosis Risk in Communities (ARIC) Study: methods and initial two years' experience. J Clin Epidemiol. 1996; 49(2):223-33. [PubMed: 8606324]

19. Braunwald E. Unstable angina. A classification. Circulation. 1989; 80(2):410-4. [PubMed: 2752565]

20. Charlson ME, Pompei P, Ales KL, MacKenzie CR. A new method of classifying prognostic comorbidity in longitudinal studies: development and validation. J Chron Dis. 1987; 40(5):37383. [PubMed: 3558716]

21. Levey AS, Coresh J, Greene T, Stevens LA, Zhang YL, Hendriksen S, Kusek JW, Van Lente F. Using standardized serum creatinine values in the modification of diet in renal disease study equation for estimating glomerular filtration rate. Ann Intern Med. 2006; 145(4):247-54. [PubMed: 16908915]

22. Killip T, Kimball JT. Treatment of myocardial infarction in a coronary care unit. A two year experience of 250 patients. Am J Cardiol. 1967; 20:457-63. [PubMed: 6059183]

23. Goodman SG, Huang W, Yan AT, Budaj A, Kennelly BM, Gore JM, Fox KA, Goldberg RJ, Anderson FA Jr. The expanded Global Registry of Acute Coronary Events: baseline characteristics, management practices, and hospital outcomes of patients with acute coronary syndromes. Am Heart J. 2009; 158(2):193-201. e1-5. [PubMed: 19619694]

24. Bertoni AG, Bonds DE, Thom T, Chen GJ, Goff DC Jr. Acute coronary syndrome national statistics: challenges in definitions. Am Heart J. 2005; 149(6):1055-61. [PubMed: 15976788]

25. Saver BG, Dobie SA, Green PK, Wang CY, Baldwin LM. No pain, but no gain? The disappearance of angina hospitalizations, 1992-1999. Med Care. 2009; 47(10):1106-10. [PubMed: 19820615]

26. Will JC, Valderrama AL, Yoon PW. Preventable hospitalizations and emergency department visits for angina, United States, 1995-2010. Prev Chronic Dis. 2013; 10:E126. [PubMed: 23886045]

27. Ko DT, Newman AM, Alter DA, Austin PC, Chiu M, Cox JL, Goodman SG, Tu JV. Secular trends in acute coronary syndrome hospitalization from 1994 to 2005. Can J Cardiol. 2010; 26(3):12934. [PubMed: 20352132]

28. Schmidt M, Jacobsen JB, Lash TL, Botker HE, Sorensen HT. 25 year trends in first time hospitalisation for acute myocardial infarction, subsequent short and long term mortality, and the prognostic impact of sex and comorbidity: a Danish nationwide cohort study. BMJ. 2012; 344:e356. [PubMed: 22279115]

29. Smolina K, Wright FL, Rayner M, Goldacre MJ. Determinants of the decline in mortality from acute myocardial infarction in England between 2002 and 2010: linked national database study. BMJ. 2012; 344:d8059. [PubMed: 22279113]

30. Hurt RD, Weston SA, Ebbert JO, McNallan SM, Croghan IT, Schroeder DR, Roger VL. Myocardial infarction and sudden cardiac death in Olmsted County, Minnesota, before and after smoke-free workplace laws. Arch Intern Med. 2012; 172(21):1635-41. [PubMed: 23108571] 
31. Hoerger TJ, Segel JE, Gregg EW, Saaddine JB. Is glycemic control improving in U.S. adults? Diabetes Care. 2008; 31(1):81-6. [PubMed: 17934153]

32. Mann D, Reynolds K, Smith D, Muntner P. Trends in statin use and low-density lipoprotein cholesterol levels among US adults: impact of the 2001 National Cholesterol Education Program guidelines. Ann Pharmacother. 2008; 42(9):1208-15. [PubMed: 18648016]

33. McWilliams JM, Meara E, Zaslavsky AM, Ayanian JZ. Differences in control of cardiovascular disease and diabetes by race, ethnicity, and education: U.S. trends from 1999 to 2006 and effects of medicare coverage. Ann Intern Med. 2009; 150(8):505-15. [PubMed: 19380852]

34. Cutler JA, Sorlie PD, Wolz M, Thom T, Fields LE, Roccella EJ. Trends in hypertension prevalence, awareness, treatment, and control rates in United States adults between 1988-1994 and 1999-2004. Hypertension. 2008; 52(5):818-27. [PubMed: 18852389]

35. Fox KA, Steg PG, Eagle KA, Goodman SG, Anderson FA Jr. Granger CB, Flather MD, Budaj A, Quill A, Gore JM. Decline in rates of death and heart failure in acute coronary syndromes, 1999-2006. JAMA. 2007; 297(17):1892-900. [PubMed: 17473299]

36. Aliprandi-Costa B, Ranasinghe I, Chow V, Kapila S, Juergens C, Devlin G, Elliott J, Lefkowitz J, Brieger DB. Management and outcomes of patients with acute coronary syndromes in Australia and New Zealand, 2000-2007. Med J Aust. 2011; 195(3):116-21. [PubMed: 21806528]

37. St Sauver JL, Grossardt BR, Leibson CL, Yawn BP, Melton LJ 3rd, Rocca WA. Generalizability of epidemiological findings and public health decisions: an illustration from The Rochester Epidemiology Project. Mayo Clin Proc. 2012; 87(2):151-60. [PubMed: 22305027]

38. Ryan J, Linde-Zwirble W, Engelhart L, Cooper L, Cohen DJ. Temporal changes in coronary revascularization procedures, outcomes, and costs in the bare-metal stent and drug-eluting stent eras: results from the US Medicare program. Circulation. 2009; 119(7):952-61. [PubMed: 19204307]

39. Riley RF, Don CW, Powell W, Maynard C, Dean LS. Trends in coronary revascularization in the United States from 2001 to 2009: recent declines in percutaneous coronary intervention volumes. Circ Cardiovasc Qual Outcomes. 2011; 4(2):193-7. [PubMed: 21304092] 


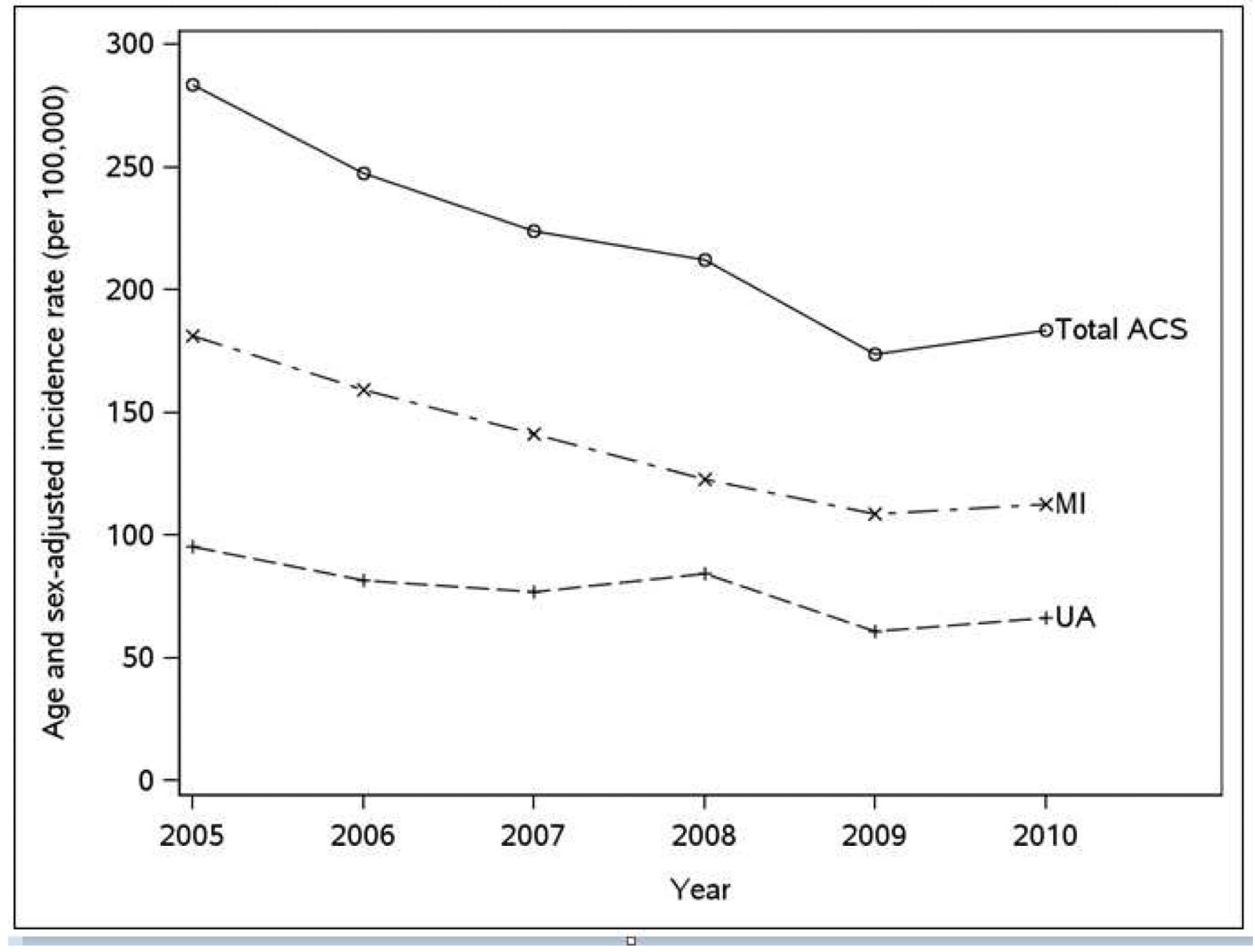

Figure 1.

Incidence of ACS by type in Olmsted County, 2005-2010. 

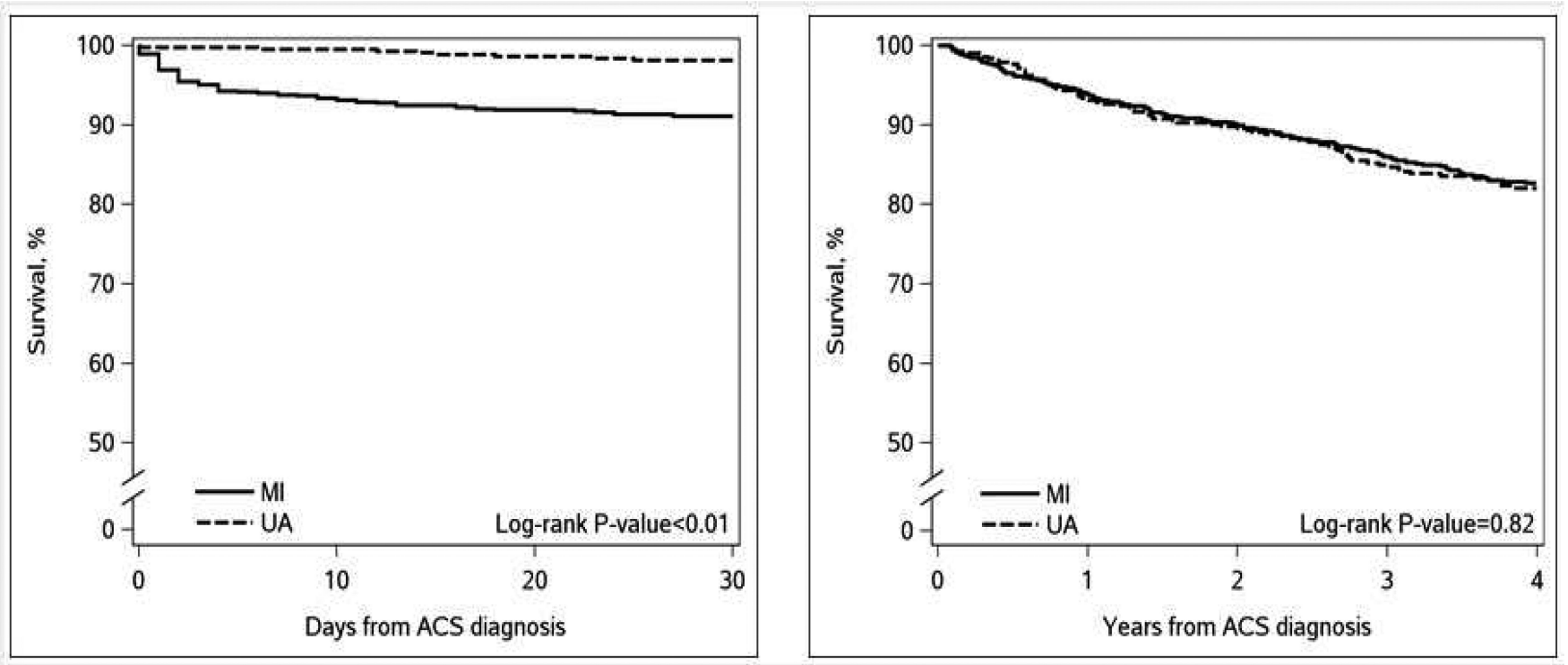

Figure 2.

Survival after ACS by type, within the first 30 days (left panel) and among 30 day survivors (right panel). 


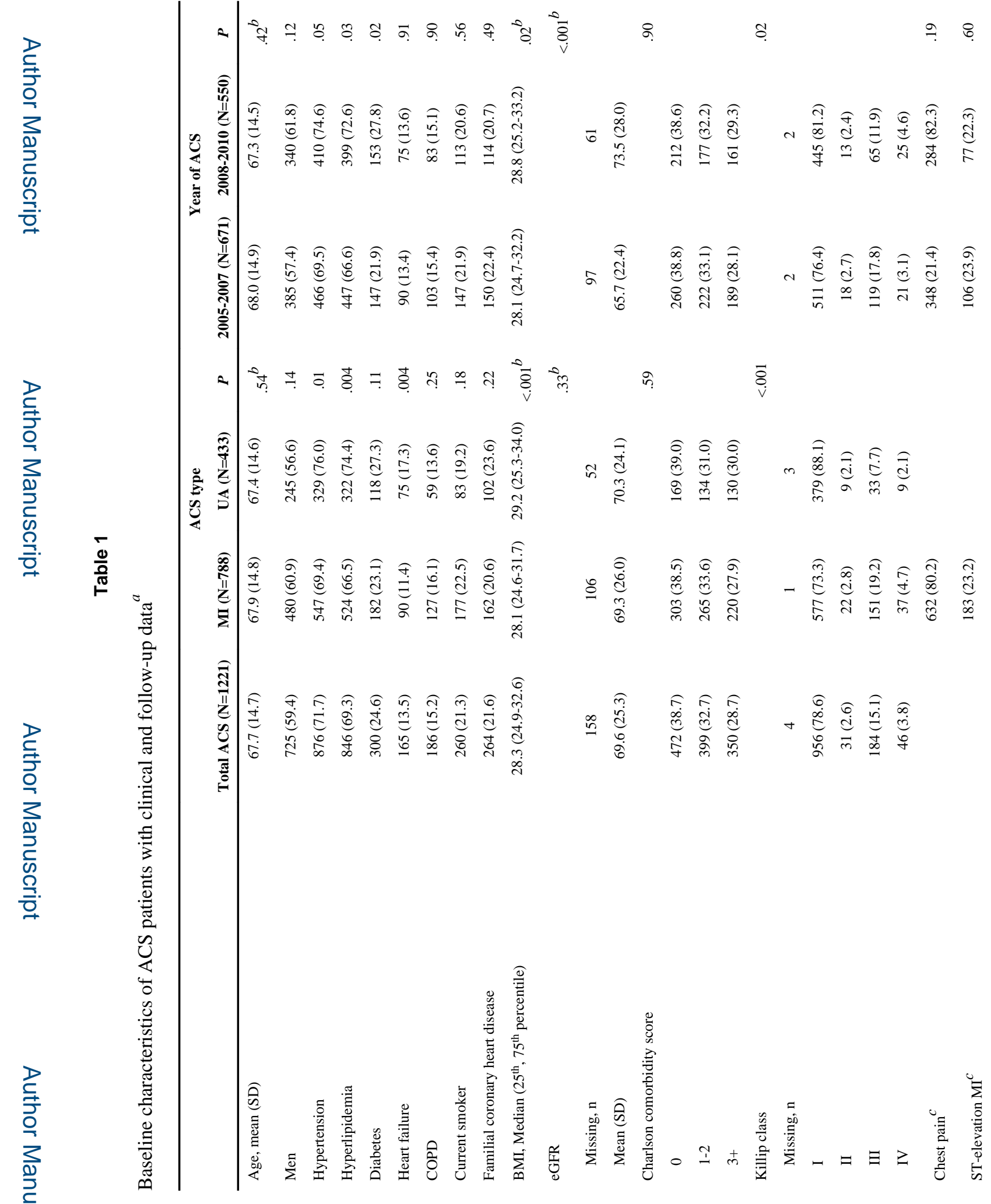

Mayo Clin Proc. Author manuscript; available in PMC 2016 May 01. 


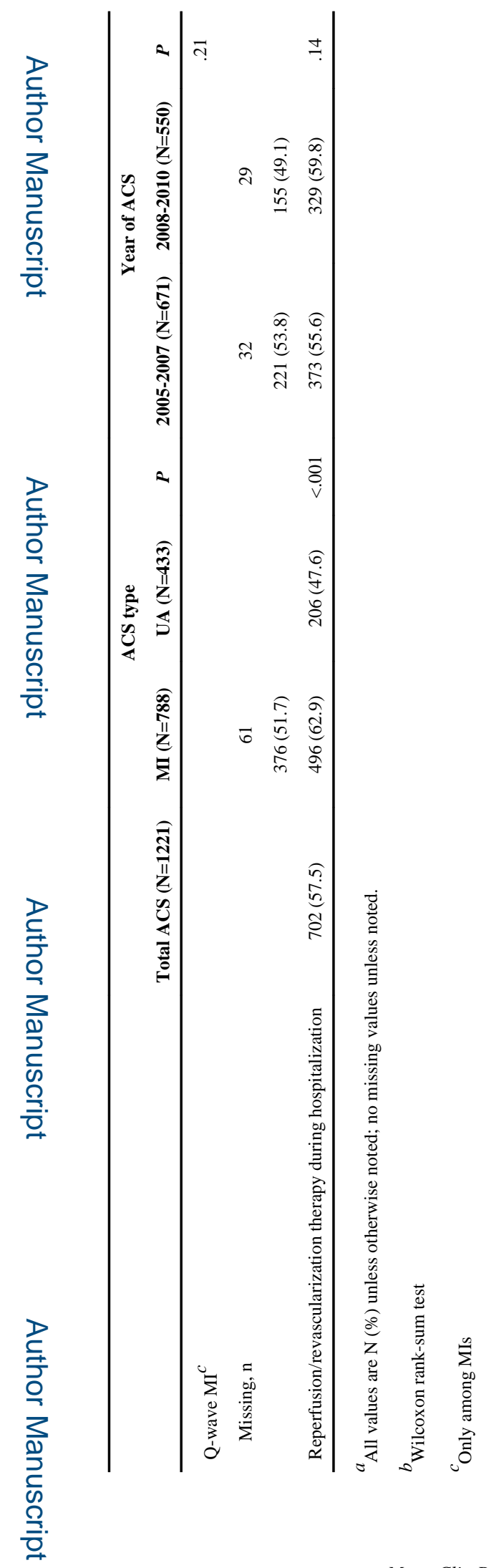

Mayo Clin Proc. Author manuscript; available in PMC 2016 May 01. 


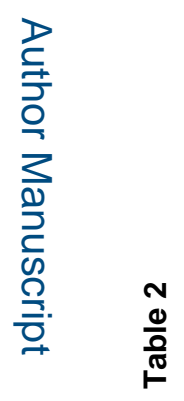

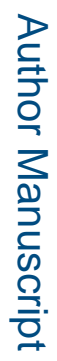

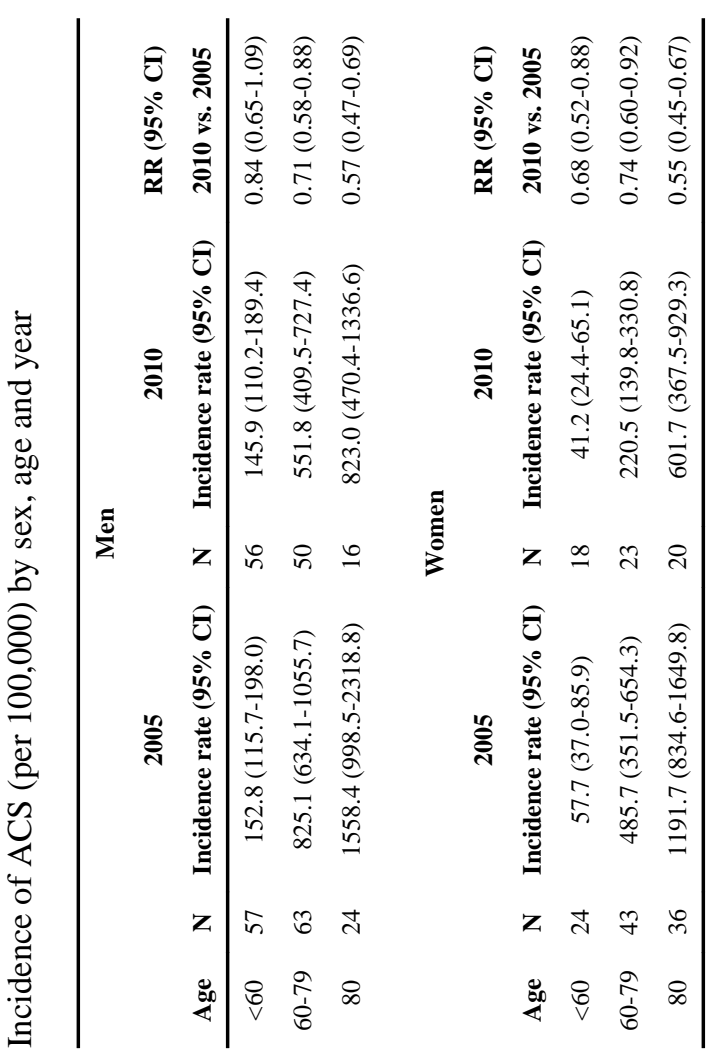

Mayo Clin Proc. Author manuscript; available in PMC 2016 May 01. 
Table 3

Hazard ratios (95\% CIs) for mortality post ACS

\begin{tabular}{clll}
\hline & Unadjusted HR (95\% CI) & Model 1 $^{\boldsymbol{a}}$ & Model 2 $^{\boldsymbol{b}}$ \\
\hline 2010 vs. 2005 & & & \\
30-day & $1.13(0.59-2.15)$ & $1.52(0.78-2.93)$ & $1.47(0.76-2.85)$ \\
Post 30-day & $0.84(0.56-1.27)$ & $0.96(0.63-1.45)$ & $0.88(0.58-1.34)$ \\
MI vs. UA & & & \\
30-day & $5.00(2.41-10.39)$ & $5.26(2.53-10.95)$ & $6.32(3.03-13.19)$ \\
Post 30-day & $1.03(0.80-1.32)$ & $1.04(0.81-1.34)$ & $1.28(0.99-1.65)$ \\
\hline
\end{tabular}

$a_{2010}$ vs. 2005 models adjusted for age, sex, ACS type; MI vs. UA models adjusted for age, sex and year.

${ }^{b}$ Additionally adjusted for Charlson comorbidity index and reperfusion/revascularization. 